\title{
Oxygen in Respiratory Care: A Personal Perspective from 40 Years in the Field
}

\author{
David J Pierson MD FAARC
}

\author{
Introduction \\ Tom Petty Showed Us the Way \\ Measuring and Monitoring Oxygen in the Body \\ Long-Term Oxygen Therapy \\ Oxygenation in the Critically Ill Patient \\ Adverse Effects of Oxygen \\ Summary
}

\begin{abstract}
Oxygen is necessary for all aerobic life, and nothing is more important in respiratory care than its proper understanding, assessment, and administration. By the early $1970 \mathrm{~s}_{\mathrm{aO}}$ had become the gold standard for clinically assessing oxygenation in the body. Since the $1980 \mathrm{~s}$ the measurement of arterial oxygen saturation by pulse oximetry has also been increasingly used as an adjunct to (but not a replacement for) $\mathbf{P}_{\mathrm{aO}}$. Despite the desirability of measuring tissue oxygenation directly, no reliable and clinically relevant such measure has emerged. The 2 areas in which oxygen has proven most important in respiratory care are long-term oxygen therapy (LTOT) and the management of potentially life-threatening hypoxemia in acute respiratory failure. That LTOT improves survival in appropriately selected patients with COPD was demonstrated by multicenter studies published more than 30 years ago, and their original selection criteria have so far not been improved upon. Severe hypoxemia in acute lung injury and ARDS can be improved by ventilation with PEEP, and also in many patients by various adjunctive techniques and alternative support strategies. However, the latter measures have not brought clear improvements in survival or other patient-relevant outcomes. In addition, the original goals of "normalizing" arterial oxygenation with high tidal volumes and lung-distending pressures have required modification as appreciation for ventilatorrelated lung injury has emerged. High concentrations of inspired oxygen may play a role in such injury, but aggressive measures to reduce them in order to avoid oxygen toxicity - which dominated ventilator management in previous decades-have been tempered in the present era of lungprotective ventilation. Although some additions and modifications have emerged, much of what we understand today about oxygen in respiratory care is owed to the pioneering work of Thomas $\mathbf{L}$ Petty more than 40 years ago. Key words: oxygen; history; COPD; acute respiratory failure; ARDS; mechanical ventilation; PEEP; long-term oxygen therapy; oxygen toxicity. [Respir Care 2013;58(1): 196-204. () 2013 Daedalus Enterprises]
\end{abstract}

\section{Introduction}

Oxygen is a central focus of respiratory care, whether the latter term is used in reference to a subject area, a

\footnotetext{
Dr Pierson is affiliated with the Division of Pulmonary and Critical Care Medicine, Department of Medicine, University of Washington, Seattle, Washington.
}

The author has disclosed no conflicts of interest. specific healthcare profession, or RESPIRATORY CARE, the journal. ${ }^{1}$ Its importance for the Journal is illustrated not only by the large numbers of original research papers and
Correspondence: David J Pierson MD FAARC, Division of Pulmonary and Critical Care Medicine, Harborview Medical Center, 325 Ninth Avenue, Box 359764, Seattle, WA 98104. E-mail: djp@u.washington.edu.

DOI: $10.4187 /$ respcare.02239 


\section{Oxygen in Respiratory Care: A Personal Perspective from 40 Years in the Field}

Open Forum abstracts involving oxygen in its pages, but also by the prominence of the topic in its conference proceedings and other special issues. The first 12 ReSPIRATORY CARE Journal conferences all dealt prominently with aspects of the measurement and clinical use of oxygen. A 1983 special issue was devoted exclusively to long-term oxygen therapy (LTOT), ${ }^{2}$ and a decade later the 12 th Journal conference was entirely about oxygenation in the critically ill patient. ${ }^{3}$ The topic of the 24 th conference was once again LTOT, ${ }^{4}$ and now, fittingly, this 50 th conference in the series addresses a full spectrum of scientific, clinical, and technological aspects of oxygen. ${ }^{5}$

I had the privilege of chairing the first Journal conference, ${ }^{6}$ as well as the postgraduate course from which the 1983 special issue was developed. ${ }^{7}$ I also served as cochair of each of the previous Journal conferences dealing entirely with oxygen. ${ }^{8,9}$ The effects, assessment, and treatment of hypoxia have been a central interest throughout my career, and I published my first article relating to this topic 40 years ago-in this journal. ${ }^{10}$ I was therefore especially pleased to be invited to attend this conference, and to have the opportunity to contribute this commentary to its proceedings.

Respiratory care has changed a great deal since I began my pulmonary fellowship in 1972. A clinician from that day who was abruptly transported to an up-to-date ICU, bronchoscopy suite, or sleep laboratory of today would surely experience disorientation in the face of all the new apparatus, terminology, variables, and interventions. It would seem a completely new world-and it is. Yet how much of its newness would represent genuine progress where the care of sick patients is concerned, and how much would just look new and different? In this commentary I will examine what has happened with respect to oxygen over the last 40 years, from the perspective of what we had and what we knew in 1972, what has occurred in the interim, and what we have and what we know today.

The history of oxygen and the genesis of our understanding of its importance and use are nicely summarized by John Heffner elsewhere in this issue. ${ }^{11}$ Here, I will deal with developments of the last 40 years from a personal perspective, having been fortunate enough to be an active participant in the field during this time and to know some of its most important players. This is not a rigorous review but rather a view through the considerable filters of my teachers, colleagues, patients, and experiences with oxygen. Four general areas seem to me to be most important: the assessment and monitoring of oxygen in the body, particularly as this affects patients with respiratory disease; long-term oxygen therapy; oxygenation in the critically ill patient; and adverse effects of oxygen administration. Before I get to those things, however, I want to return briefly to the question alluded to above: How much of what we have and what we know about oxygen today is really new, and how much has actually been there all along but imperfectly understood or appreciated?

\section{Tom Petty Showed Us the Way}

It was my extraordinarily good fortune to finish my medicine residency and do my fellowship at the University of Colorado in Denver. There I had the opportunity to learn pulmonary and critical care medicine from Thomas $\mathrm{L}$ Petty MD (1932-2009), one of the field's true giants worldwide. ${ }^{12,13}$ It is tempting to say that Tom Petty had figured out everything that was really important about oxygen by the time I arrived. This would of course be a gross exaggeration, but I will explain why I think it is mostly true.

In July 1972, when I started as his fellow at Colorado General Hospital, Dr Petty had just reached the age of 40 and been appointed head of the pulmonary division. By that time he had already established one of the world's first intensive respiratory care units, set up one of the initial pulmonary rehabilitation programs anywhere, demonstrated the benefits of LTOT on survival and quality of life in COPD, described and named the adult respiratory distress syndrome (now the acute respiratory distress syndrome, ARDS), and shown how the application of PEEP could alleviate life-threatening hypoxemia in that condition. Forty years ago, Tom Petty had already placed his personal stamp on the field, and his contributions would only increase in the succeeding decades-including in part (but only in part) his authorship of 800 papers, 30 books, and hundreds of book chapters and editorials. ${ }^{12}$

Dr Petty's importance to respiratory care-and to the subject of oxygen-derives prominently from 5 attributes. First, he devoted his energies not to theoretical concepts or rare diseases but to bread-and-butter conditions like COPD and acute respiratory failure that affected large numbers of patients and that clinicians had to contend with on an everyday basis. Second, he emphasized the importance of basing management on the disordered physiology manifested by patients with respiratory disease. Third, and especially important for respiratory care, he stressed that to manage these conditions optimally required a multidisciplinary, collaborative approach. In his 1971 book, Intensive and Rehabilitative Respiratory Care, he wrote,

The development of an organized team-approach for management of patients with acute respiratory failure has been a major advance of today's medicine and has provided the arena for systematic physiologically oriented care. The disciplines of internal medicine, surgery, anesthesiology, nursing care, inhalation therapy, and physical medicine and rehabilitation all come to bear on problems presented by each individual case. ${ }^{14}$, page $\mathrm{v}$ 
The fourth thing that set Tom Petty apart was his dedication to "taking the message to the trenches." He was an education entrepreneur. By the time I arrived in Colorado he had met and personally interacted with virtually every primary care provider in the state, as well as many of its nurses and respiratory therapists. He and his respiratory care team trained hundreds of physicians and nonphysicians, both in their Denver-based courses on the practical management of respiratory problems and in dozens of visits to community hospitals and clinics throughout Colorado. ${ }^{15-17}$ As he stated in the preface to his first book, "The major aim of this book is to show how respiratory failure may be efficiently managed in general hospitals and how practical care can be applied at the bedside." 14 , page vi These efforts increased general awareness of spirometry, arterial blood gases (ABGs), physiologically based oxygen therapy, and recognition of acute respiratory failure-all of which were new to practitioners in the late 1960s — and it helped to put Denver on the map as an international center for pulmonary and critical care medicine.

Finally, perhaps like no one else, Dr Petty realized the critical importance of industry in respiratory care. More than in most other healthcare fields, the development, evaluation, and introduction of medical devices and other commercial products are central and inextricable components of the optimal evaluation and management of patients with disorders affecting the respiratory system. Rather than assuming an adversarial posture with respect to interactions between commercial interests and those of clinicians and their patients, Dr Petty worked with engineers and manufacturers as colleagues with common goals. This led to numerous innovations in oxygen therapy and mechanical ventilation as well as to enduring links among professional groups, industry, and regulators that addressed practical issues affecting patients with lung disease.

In discussing different aspects of oxygen in the following sections, I will allude to ways in which these 5 attributes contributed to Tom Petty's enormous impact on the field. I will also point out ways in which what he taught us 40 years ago contained the essence of what we know today about oxygen.

\section{Measuring and Monitoring Oxygen in the Body}

The modern era with respect to oxygen began when it became possible to measure oxygen tension in the blood. Symptoms and physical signs are notoriously inaccurateand often misleading - in detecting the presence of hypoxemia and gauging its severity. An electrode for measuring $\mathrm{P}_{\mathrm{O}_{2}}$ had been introduced in 1954 by Leland Clark, ${ }^{18}$ but a decade later this was still mainly found in physiology laboratories. As a medical resident in 1960, Tom Petty had a patient whose elevated hematocrit had been ascribed to polycythemia vera. Suspecting that it was actually secondary erythrocytosis in response to chronic hypoxemia, Petty confirmed this by drawing a blood sample from the patient's radial artery and measuring the $\mathrm{P}_{\mathrm{O}_{2}}$ with a Clark electrode. Although it correctly diagnosed his patient's problem, this "extreme" intervention got Tom Petty suspended from his residency. ${ }^{12}$ Although he was later reinstated, this episode illustrates the state of pulmonary medicine at the time, and makes it easier to appreciate how the subsequent widespread availability of ABGs revolutionized respiratory care. ${ }^{11,19}$

By 1972, $\mathrm{P}_{\mathrm{aO}_{2}}$ was accepted as the gold standard for assessing the state of oxygenation in the body. It was used to diagnose acute respiratory failure and to direct mechanical ventilation in the ICU, and was becoming more widely used in COPD to guide LTOT. ${ }^{14}$ Although not available in every hospital's clinical laboratory, ABGs could be obtained in pulmonary function laboratories and in many ICUs. Measurement of $\mathrm{P}_{\mathrm{aO}}$ still required an arterial puncture, however, and there was great interest in developing noninvasive techniques for assessing oxygenation in the body.

The Hewlett-Packard ear oximeter, introduced in the mid-1970s, was the first practical noninvasive oxygenation monitor. ${ }^{20}$ Although valuable for exercise testing and research applications, it was bulky, heavy, and illsuited for everyday clinical use. Other, somewhat less cumbersome ear oximeters became available, but the big breakthrough was the introduction of pulse oximetry in 1983. This ushered in a new era in oxygenation monitoring, ${ }^{19}$ and oxyhemoglobin saturation measured by pulse oximetry $\left(\mathrm{S}_{\mathrm{pO}_{2}}\right)$ was soon hailed as "the 5th vital sign." 21 Ubiquitous now in all healthcare settings, at least in this country, pulse oximeters have now spread into the public domain, where one may buy a fingertip model on the Internet for as little as $\$ 20$. The use of pulse oximetry by the lay public_-in athletics, travel, and other non-medical, "lifestyle" applications_ c crosses into murky territory with respect to legality, because the Food and Drug Administration still technically regards oximeters as medical devices to be dispensed only on prescription by a licensed physician. However, there is no question that this technology has revolutionized the assessment of oxygenation in the body, not least in the management of patients with respiratory disease.

The ability to assess oxygenation frequently or continuously has its problems, however, particularly in acutely ill patients. ${ }^{19}$ In the current, intensively monitored environment of the ICU, changes in the variables being monitored often trigger new tests or alterations in management, even when bedside assessment does not suggest an acute deterioration. This was brought home 30 years ago in a study of ABG variability in 29 intubated ICU patients who were ill enough to have an arterial line but clinically stable 


\section{Oxygen in Respiratory Care: A Personal Perspective from 40 Years in the Field}

at the time of assessment. ${ }^{22}$ With no alterations in position or other interventions, the mean range of $\mathrm{P}_{\mathrm{aO}}$ values in these patients, in 6 samples drawn over $50 \mathrm{~min}$, was

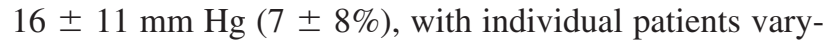
ing up to $45 \mathrm{~mm} \mathrm{Hg.}{ }^{22}$ Some of these variations, which presumably reflect "normal" physiologic variation in patients with acute illness, rather than changes in clinical status, would have precipitated changes in management according to current protocols. A subsequent study incorporating pulse oximetry as well as $\mathrm{ABGs}^{23}$ corroborated these findings and emphasized the pitfalls of using oxygenation data in isolation for making clinical decisions.

Of course, neither $\mathrm{P}_{\mathrm{aO}}$ nor $\mathrm{S}_{\mathrm{pO}_{2}}$ completely evaluates the status of oxygenation in the body. As Petty stated in 1971, "The rational use of oxygen in acute respiratory failure demands an understanding of tissue oxygen transport, which is a function of cardiac output and oxygen content." 14 , page 31 What we would really like to measure is oxygenation at the tissue level. However, although interest continues in this area, ${ }^{24}$ the monitoring of $\mathrm{P}_{\mathrm{O}_{2}}$ or other oxygenation variables in various tissues has yet to attain a level of clinical accuracy and reliability to be useful in routine care, particularly in critically ill patients. ${ }^{19}$

\section{Long-Term Oxygen Therapy}

Along with a handful of other clinician-investigators in the United States and the United Kingdom, Tom Petty began treating patients with severe COPD and chronic hypoxemia with oxygen at home in the mid-1960s..$^{25}$ In 6 patients, he and his colleagues demonstrated that LTOT could reduce pulmonary artery pressures and secondary polycythemia. ${ }^{26} \mathrm{He}$ added ambulatory oxygen therapy to domiciliary administration, ${ }^{27}$ and became a fervent advocate for this approach to achieving true continuous oxygen therapy long-term. Subsequently, he showed improved survival in patients given LTOT, compared to historical controls with equivalent disease severity. ${ }^{28}$

That survival among patients with COPD and chronic hypoxemia could be increased by LTOT was subsequently demonstrated convincingly by the multicenter Nocturnal Oxygen Therapy Trial (NOTT) ${ }^{29}$ and the similar trial conducted by the Medical Research Council (MRC) in the United Kingdom. ${ }^{30}$ The patients in these studies had $\mathrm{P}_{\mathrm{aO}_{2}}$ values of $55 \mathrm{~mm} \mathrm{Hg}$ or less breathing air while clinically stable; in the NOTT patients were also enrolled who had values of 55-59 $\mathrm{mm} \mathrm{Hg}$ if they had evidence of end-organ effects (right heart dysfunction or polycythemia) from chronic hypoxemia. Taken together, the NOTT and MRC trials showed that survival could be increased by LTOT used at least $12-15 \mathrm{~h} / \mathrm{d}$, and that more hours of daily use produced an incremental survival benefit. ${ }^{11}$

The NOTT and MRC studies got it right in terms of $\mathrm{P}_{\mathrm{aO}_{2}}$ selection criteria, and with good physiologic justification.
At normal $\mathrm{pH}$, hemoglobin's oxygen carrying capacity falls off progressively once $\mathrm{P}_{\mathrm{aO}_{2}}$ drops below the "shoulder" of the oxyhemoglobin saturation curve, at $55-59 \mathrm{~mm} \mathrm{Hg}$. To date no study of similar patients with $\mathrm{P}_{\mathrm{aO}}$ values of $60 \mathrm{~mm} \mathrm{Hg}$ or more has shown a survival benefit from LTOT, although only one such trial of strong design has been reported. ${ }^{31}$ The multicenter Long-Term Oxygen Therapy Trial (LOTT), intended to address this issue, ${ }^{32}$ has been underway for several years, but at the time of writing is still enrolling patients. Although LTOT is reimbursed and widely prescribed for patients who reach the hypoxemia threshold only during exercise or when asleep, so far there is no evidence from properly conducted studies that this increases survival. ${ }^{11,32}$ Thus, what we know about the selection of patients for LTOT we mainly learned over 30 years ago from the NOTT.

A funny thing happened on the way to the Medicare reimbursement criteria for LTOT: $\mathrm{S}_{\mathrm{pO}_{2}}$ became an alternative for $\mathrm{P}_{\mathrm{aO}}$. I have not been able to find out how this happened, but it is probably an interesting story. At the time the Medicare LTOT reimbursement guidelines were first released in $1985,{ }^{33}$ all research on LTOT had used $\mathrm{P}_{\mathrm{aO}_{2}}$ exclusively, and no guideline or other leading published source on patient selection criteria ${ }^{34-36}$ had even mentioned saturation as a potential alternative. As stated earlier, the first pulse oximeters were marketed in 1983; the first advertisement I can find in this Journal appeared in November of that year. Yet little more than a year later the Health Care Financing Administration (now the Centers for Medicare and Medicaid Services) made an $\mathrm{S}_{\mathrm{pO}_{2}}$ of $85 \%$ an equivalent qualifying criterion to $\mathrm{P}_{\mathrm{aO}_{2}}$ of $55 \mathrm{~mm} \mathrm{Hg},{ }^{33}$ and it became the law of the land.

The $85 \% \mathrm{~S}_{\mathrm{pO}_{2}}$ threshold proved to be a problem. At $\mathrm{pH} 7.40$ and $\mathrm{P}_{\mathrm{aO}_{2}} 55 \mathrm{~mm} \mathrm{Hg}$, oxyhemoglobin saturation is closer to $88 \%$ than $85 \%$. A consensus conference convened by Dr Petty that included leading clinicians as well as representatives from industry and other interested parties, urged that the threshold criterion be increased to $88 \%{ }^{37}$ Shortly thereafter, Carlin and colleagues confirmed the appropriateness of this recommendation by showing that, among 55 chronically hypoxemic patients, $80 \%$ of those who met the $\mathrm{P}_{\mathrm{aO}}$ criterion of $55 \mathrm{~mm} \mathrm{Hg}$ or less had $\mathrm{S}_{\mathrm{pO}_{2}}$ values exceeding $85 \% .{ }^{38}$ The Medicare saturation threshold was subsequently raised to $88 \% .{ }^{39}$

Oxygen for LTOT can come from compressed-gas cylinders, liquid oxygen reservoirs, or oxygen concentrators. The last of these has proven to be the most cost-effective and is now most often used worldwide. After several decades of stagnation, the introduction of new devices for delivering oxygen at home has accelerated during the last decade, and there are now many options, particularly for ambulatory oxygen delivery. The balance between reimbursement under current Medicare regulations (which essentially determines what private insurers and other payers 


\section{Oxygen in Respiratory Care: A Personal Perspective from 40 Years in the Field}

will pay) and the industry's response still largely determines the individual patient's experience with LTOT.

Extrapolations from the NOTT data suggest that, if a patient with COPD were begun on LTOT as soon as chronic hypoxemia criteria were met, his or her increased survival should amount to several years. However, as brought out during the discussion at this conference, ${ }^{40}$ the best data we have indicate that the average Medicare patient who receives LTOT stays on it for less than a year prior to death. This illustrates a big gap between what we know and what we do with respect to patient selection for and follow-up on this life-extending therapy. ${ }^{41}$

\section{Oxygenation in the Critically Ill Patient}

Here Tom Petty's impact has been at least as great as with LTOT. His initial description of ARDS, with surgeon David Ashbaugh and 2 pulmonary fellows, ${ }^{42}$ remains uncannily accurate in terms of our present understanding of the syndrome, and has been cited over 1,500 times in other publications, according to the Web of Science. ${ }^{43}$

As new faculty members at the University of Colorado in 1964, Petty and Ashbaugh had one patient with multiple trauma, and a second with hemorrhagic pancreatitis, both of whom developed respiratory distress, severe hypoxemia, bilateral pulmonary infiltrates, and stiff lungs that could not be adequately supported with the usual pressure-targeted ventilators. Retrieving an unused 1954 Engstrom volume ventilator from storage, they showed that both patients could be adequately ventilated and that their hypoxemia improved on the addition of PEEP. ${ }^{44} \mathrm{Al}-$ though both of these initial patients died, over the next year several others with similar presentation survived with volume ventilation and PEEP. The similarity of the lungs of these patients to those of infants with (infant) respiratory distress syndrome prompted Petty and Ashbaugh to name their patients' illness the adult respiratory distress syndrome. 42,44

Based largely on the experience reported by Petty and colleagues, volume ventilation with PEEP became the primary approach to the management of patients with ARDS. ${ }^{45-47}$ Ventilation, $\mathrm{F}_{\mathrm{IO}_{2}}$, and PEEP were adjusted to keep ABG values as close to normal as possible. A few years previously it had been shown that, in anesthetized patients with normal lungs, larger-than-physiologic tidal volumes ameliorated the microatelectasis and elevated alveolar-to-arterial $\mathrm{P}_{\mathrm{O}_{2}}$ difference that would otherwise develop. ${ }^{48}$ This finding was applied to patients with acute respiratory failure, and large-tidal-volume ventilation became the standard of ICU management. Thus, ventilator management in ARDS during the 1970s and 1980s typically employed tidal volumes of $10-15 \mathrm{~mL} / \mathrm{kg}$ (or more), and as much PEEP as was required to permit the $\mathrm{F}_{\mathrm{IO}_{2}}$ to be decreased to a "safe" level. Minute ventilations exceeding
$20 \mathrm{~L} / \mathrm{min}$ and PEEP levels of $15-20 \mathrm{~cm} \mathrm{H}_{2} \mathrm{O}$ or higher were commonplace in many units during this time.

But what was a "safe" $\mathrm{F}_{\mathrm{IO}_{2}}$, above which more PEEP needed to be employed in an attempt to reduce it? Individual clinicians varied a lot in their approaches to this question. In 1993, the American College of Chest Physicians convened an international consensus conference on mechanical ventilation. ${ }^{49}$ Numerous areas of consensus were reached with respect to managing patients with acute respiratory failure. However, despite repeated attempts and different ways of posing the question, it was not possible for the 15 participants to agree-even in general terms - on what the minimum $\mathrm{F}_{\mathrm{IO}_{2}}$ was that could be tolerated for 24 hours or more. Some would accept the use of $100 \%$ oxygen for up to 24 hours if necessary to adequately oxygenate the blood, or $70 \%$ for up to 3 days. Others were adamant about the need for active measures to get the $\mathrm{F}_{\mathrm{IO}_{2}}$ down to 0.5 or even 0.4 within 24 hours if this were at all possible.

The last 4 decades have seen the introduction of literally dozens of new approaches to and modes of mechanical ventilation, as well as numerous adjunctive measures, for managing patients with acute respiratory failure. Of the hundreds of publications generated by these "innovations," one stands out as describing the most important genuine advance in mechanical ventilation-perhaps ever. This is the report of the ARDS Network's study demonstrating that "lung-protective ventilation" with lower tidal volumes and airway pressures than previously used substantially improved survival in patients with acute lung injury and ARDS. ${ }^{50}$ Although the use of PEEP is clearly life-saving in ARDS, as demonstrated by Petty, it is now also clear that patient survival can be affected adversely by other aspects of ventilatory support as practiced in the years following his initial publications.

Although ARDS is defined in part by hypoxemia, relatively few patients die of refractory gas-exchange failure. ${ }^{51}$ Still, some do. Critical hypoxemia may be thought of as a situation in which hypoxemia per se threatens the life of a patient regardless of the nature of the illness causing it. However, in a practical sense, critical hypoxemia can be thought of as that degree of oxygenation impairment that prompts the clinician to "do something more" than is already being done, or to switch to a different management approach, in an attempt to raise the $\mathrm{P}_{\mathrm{aO}_{2}}$. Just as individual clinicians vary in their application of this concept, they also vary in choosing from among the numerous interventions and management approaches currently available. ${ }^{52-56}$

In thinking about oxygenation in the critically ill patient, it seems intuitive that improving oxygenation would correspondingly improve the outcome. However, it turns out that this is not necessarily the case. Of the numerous ventilatory and non-ventilatory interventions invoked in 


\section{Oxygen in Respiratory Care: A Personal Perspective from 40 Years in the Field}

managing refractory hypoxemia, ${ }^{52-56}$ all of which improve arterial oxygenation in at least some patients, none has been clearly shown to improve survival or other outcomes that would matter to patients or their families, compared to conventional lung-protective ventilation. In fact, some measures that make arterial oxygenation better actually worsen survival, as was shown by the large-tidal-volume, higherpressure group in the original ARDS Network trial. ${ }^{50}$

\section{Adverse Effects of Oxygen}

\begin{abstract}
The proper use of oxygen in clinical medicine demands precision of administration and careful monitoring so that tissue oxygen transport is adequately maintained without harmful effects from imprecise and excessive use. ${ }^{14}$, page 31
\end{abstract}

Concern about these "harmful effects from imprecise and excessive use" has driven much of the history of oxygen use over the last 40 years. In my opinion, the level of concern has far outweighed the actual risk, with both lowflow home use and oxygen administration to critically ill patients in the ICU.

Fear of $\mathrm{CO}_{2}$ retention was a major impediment to widespread adoption of LTOT in the 1960s and 1970s. It was thought that patients with COPD and chronic hypoxemia had lost their hypercapnic respiratory drive and were thus dependent on hypoxemia for continued ventilation, such that relieving this stimulus to breathe would result in hypoventilation, perhaps fatally. Patients with exacerbations of severe COPD, particularly those with chronic hypercapnia, typically do become more hypercapnic when acute hypoxemia is relieved, particularly when oxygen administration is excessive. However, this is predominantly a phenomenon of acute-on-chronic ventilatory failure, rather than stable COPD, and can almost always be avoided if $\mathrm{P}_{\mathrm{aO}}$ is not raised acutely above $60-65 \mathrm{~mm} \mathrm{Hg}$.

In the 1970s it was shown that COPD patients with stable chronic hypercapnia and hypoxemia who were given low-flow oxygen sufficient to increase $\mathrm{P}_{\mathrm{aO}_{2}}$ into this range, and no higher, did not experience $\mathrm{CO}_{2}$ retention sufficient to cause a clinically relevant decrease in arterial $\mathrm{pH} .{ }^{57}$ The mechanism for $\mathrm{CO}_{2}$ retention in this setting has long been debated. It is almost certainly not due to suppression of hypoxic ventilatory drive-at least entirely-and ventilation-perfusion abnormalities likely contribute substantially. ${ }^{58,59}$

The possibility that low-flow supplemental oxygen therapy might be capable of causing parenchymal oxygen toxicity was raised by Dr Petty and his colleagues in an autopsy study showing suspicious histological changes in the lungs of patients treated for several years with LTOT. ${ }^{60}$ These changes had not been observed in patients dying with COPD who had not received LTOT. Although similar findings were published by another group, ${ }^{61}$ nothing further has since appeared, and the notion of oxygen toxicity from LTOT is seldom mentioned today.

Home oxygen therapy can cause nasal drying and nosebleeds, and contact dermatitis from nasal cannulae has been reported. ${ }^{62,63}$ However, the most serious medical problem associated with LTOT is cutaneous burns related to oxygen use while smoking. Although oxygen does not explode, as sometimes claimed in the media, it does facilitate combustion, and may contribute both to serious injury and to property damage. ${ }^{64}$ It seems to me, though, that the most important adverse effects related to LTOT are failure of patients' physicians to prescribe it when indicated, lack of access because of insurance or provider issues, and failure of patients to use it as prescribed. These problems likely result in far more morbidity and mortality than any hazards of the oxygen itself.

The earlier discussion of disagreement among leading experts about what constituted a "safe" $\mathrm{F}_{\mathrm{IO}_{2}}$ in managing a patient with acute respiratory failure was about concern for pulmonary oxygen toxicity. Necessary to sustain aerobic life, oxygen can also kill, as experiments with animals showed many years ago. ${ }^{65,66}$ Evidence for airway and parenchymal injury becomes evident after only a few hours in normal humans exposed to $100 \%$ oxygen. ${ }^{66,67}$ Parenchymal oxygen toxicity in experimental animals has histological characteristics similar to those of ARDS, making recognition of oxygen-induced injury difficult in critically ill patients. Decades ago this knowledge set the stage for controversy as to the risk of oxygen toxicity from the clinical use of oxygen in high concentrations, and this controversy has continued.

The desire to avoid oxygen toxicity was a main driver for the use of high levels of PEEP in the 1970s and 1980s. Higher levels of PEEP, with their greater risk for hemodynamic compromise, led to the need for more aggressive fluid and pressor support, and with it the need for more invasive hemodynamic monitoring. High PEEP was often accompanied by high minute ventilation in this era of large delivered tidal volumes, and the resultant pulmonary hyperinflation often led to pneumomediastinum, subcutaneous emphysema, and pneumothorax. It was common for patients with ARDS to have chest tubes-sometimes several of them-and bronchopleural air leaks were frequent. A review of 3 years' experience at Harborview Medical Center yielded 39 cases of bronchopleural fistula in mechanically ventilated patients, many of which developed in the course of management of ARDS. ${ }^{68}$ In 8 patients the leaks exceeded $500 \mathrm{~mL}$ per breath, and all 8 of those patients died. ${ }^{68}$

Many of the complications associated with mechanical ventilation appear to have decreased in the era of lungprotective ventilation. Evidence on the incidence of pneumothorax, bronchopleural fistula, and other forms of clin- 


\section{Oxygen in Respiratory Care: A Personal Perspective from 40 Years in the Field}

ical barotrauma in ventilated patients over time is scant, although at centers that manage large numbers of such patients the impression is that it has decreased in recent decades. ${ }^{69}$

Given how difficult it is to identify oxygen toxicity in a critically ill patient, it is tempting to question how important a clinical problem it really is. And given the multiplicity of potentially life-threatening complications associated with the things clinicians do to minimize $\mathrm{F}_{\mathrm{IO}_{2}}$ in order to avoid oxygen toxicity-from hemodynamic compromise and the complications of invasive hemodynamic monitoring, to barotrauma, to delayed weaning from ventilatory support while higher levels of PEEP are taperedone might wonder whether it is all worth it. More to the point, it may be that far more injury has been done to patients by the measures well-meaning clinicians have taken to avoid oxygen toxicity than would ever have occurred from the oxygen itself.

On rounds, a generation of medical trainees and respiratory therapists has heard me compare oxygen toxicity in the ICU to the Sasquatch, or Bigfoot, a well-known figure here in the Northwest. That is, as with the Sasquatch, ICU clinicians are well aware of oxygen toxicity-we know what it is supposed to look like, we are afraid of it, and we take special steps to avoid it when we venture into its presumed territory-but it is doubtful whether anyone has ever actually seen it.

The Sasquatch analogy is probably too glib, and, as discussed by Kallet and Matthay elsewhere in this issue, evidence is emerging that high levels of molecular oxygen and reactive oxygen species do injure lung tissue in critically ill patients. ${ }^{67}$ In the last 20 years attention has turned from barotrauma, conceptually a purely mechanical problem, to biotrauma. ${ }^{70}$ The latter, although initiated by excessive lung stretch and shear forces, is a much more complex process, involving mediators of tissue injury and affecting multiple organs in the body. ${ }^{67,70,71}$ Fortunately, it appears that the use of low-tidal-volume, lower-pressure, lung-protective ventilation may diminish the threat of further lung injury, whatever its mechanism, in patients with acute respiratory failure.

\section{Summary}

Oxygen is as important as any single word that might be applied to respiratory care. Much of what we know today about oxygen's effects in the body and its therapeutic use grew out of insights, discoveries, and innovations by Dr Tom Petty. Dr Petty turned out to be mistaken about the value of corticosteroids in treating ARDS, and his enthusiasm for PEEP led to widespread adoption of ventilation practices that turned out to be injurious to the lungs. However, on most things he was right. He stressed a multidisciplinary approach to patient care based on an under- standing of physiology, and emphasized practical bedside instruction of primary care providers in community hospitals and clinics. He understood the importance of collaboration with the inventors and producers of devices used in respiratory care. He saw what was important in COPD and acute respiratory failure, and he pointed the way to much of the progress that has taken place in respiratory care during the last 40 years.

Based on what I learned from Tom Petty, and tempered by my experience and understanding of the field and its literature over the last 40 years, the following seem to me to be key points about oxygen with respect to respiratory care:

- $\mathrm{P}_{\mathrm{aO}_{2}}$ remains the gold standard for assessing arterial oxygenation, although pulse oximetry has proved to be a valuable adjunct with wide application.

- No direct monitor of tissue oxygenation has thus far proven to be reliable and clinically valuable in the routine care of adult patients in the ICU.

- The LTOT patient selection criteria for the NOTT have withstood the test of time and have not been extended or improved upon.

- New devices for portable and ambulatory oxygen therapy offer the potential for substantial patient benefit, if ways can be found to make them affordable and available to the patients who need them.

- Ventilation with judiciously adjusted PEEP, plus lower tidal volumes and pressures than used in previous decades, saves lives in acute lung injury and ARDS.

- The administration of low-flow oxygen to patients with COPD and stable chronic hypoxemia is safe, and its benefits far outweigh its potential adverse effects.

- We still do not know what $\mathrm{F}_{\mathrm{IO}_{2}}$ is "safe" in managing patients with severe hypoxemia with respect to possible oxygen toxicity, although current lung-protective ventilation results in less injurious measures to avoid it.

\section{REFERENCES}

1. Pierson DJ. What is respiratory care? [editorial]. Respir Care 1998; 43(1):17-19.

2. Special issue: Long-term oxygen therapy: a world view. Respir Care 1983;28(7):857-930.

3. Respiratory Care Journal Conference. Oxygenation in the critically ill patient. Part 1 and Part 2. Respir Care 1993;38(6):587-704 and 38(7):739-846.

4. Respiratory CARE Journal Conference. Long-term oxygen therapy. Part 1 and Part 2. Respir Care 2000;45(1):28-126 and 45(2):172-245.

5. RespiRAtory CARE Journal Conference. Oxygen. Respir Care 2013; 58(1):18-204.

6. RESPIRATORY CARE Journal Conference. Complications of respiratory therapy. Respir Care 1982;27(4):399-470. 


\section{Oxygen in Respiratory Care: A Personal Perspective from 40 Years in the Field}

7. Pierson DJ. Long-term oxygen therapy: a world view [editorial]. Respir Care 1983;28(7):857-858

8. Pierson DJ. Normal and abnormal oxygenation: physiology and clinical syndromes. Respir Care 1993;38(6):587-599; discussion 599-602.

9. Petty TL, Pierson DJ. Foreword: New science and technology in long-term oxygen therapy. Respir Care 2000;45(1):28.

10. Pierson DJ. Respiratory stimulants: review of the literature and assessment of current status. Respir Care 1973;18:549-554.

11. Heffner JE. The story of oxygen. Respir Care 2013;58(1):18-30; discussion 30-31.

12. Schwarz MI. Thomas L Petty MD (1932-2009). A tribute. Am J Respir Crit Care Med 2010;81:425.

13. Iseman MD, Goode JT Jr. Thomas L Petty. Extraordinary clinician, bold innovator, inspiring educator, loyal friend, world-class raconteur, and Waltonesque angler. Chest 2010;137(6):1255.

14. Petty TL. Intensive and rehabilitative respiratory care. Philadelphia: Lea \& Febiger; 1971.

15. Petty TL, Neff TA, Nett LM, Tyler ML. A program for community training in respiratory care. Chest 1973;64(5):636-640.

16. Petty TL. Training in respiratory care. Am Rev Respir Dis 1968;98: 1060-1061.

17. Farrington JF, Mattusch L, Petty TL. Comprehensive respiratory care in the small community hospital? Yes, it can be done. Bull Natl Tuberc Respir Dis Assoc 1971;57:8-13.

18. Severinghaus JW, Astrup PB. History of blood gas analysis. IV. Leland Clark's oxygen electrode. J Clin Monit Comput 1986;2(2): 125-139.

19. Hess DR. Detection and monitoring of hypoxemia and oxygen therapy. Respir Care 2000;45(1):65-80; discussion 80-83.

20. Saunders NA, Powles AC, Rebuck AS. Ear oximetry: accuracy and practicability in the assessment of arterial oxygenation. Am Rev Respir Dis 1976;113(6):745-749.

21. Neff TA. Routine oximetry: a fifth vital sign? Chest 1988;94(2):227.

22. Thorson SH, Marini JJ, Pierson DJ, Hudson LD. Variability of arterial blood gas values in stable patients in the ICU. Chest 1983; 84(1):14-18.

23. Hess D, Agarwal NN. Variability of blood gases, pulse oximeter saturation, and end-tidal carbon dioxide pressure in stable, mechanically ventilated trauma patients. J Clin Monit 1992;8(2):111-115.

24. Martini RP, Deem S, Treggiari MM. Targeting brain tissue oxygenation in traumatic brain injury. Respir Care 2013;58(1):162-169; discussion 169-172.

25. Bigelow DB, Petty TL, Levine BL, Filley GF, Finigan MM. The effect of oxygen breathing on arterial blood gases in patients with chronic airway obstruction living at 5,200 feet. Am Rev Respir Dis 1967;96(1):28-34

26. Levine BE, Bigelow DB, Hamstra RD, Beckwitt HJ, Mitchell RS, Nett LM, et al. The role of long-term continuous oxygen administration in patients with chronic airway obstruction with hypoxemia. Ann Intern Med 1967;66(4):639-650.

27. Petty TL, Finigan MM. Clinical evaluation of prolonged ambulatory oxygen therapy in chronic airway obstruction. Am J Med 1968; 45(2):242-252.

28. Neff TA, Petty TL. Long-term continuous oxygen therapy in chronic airway obstruction. Mortality in relationship to cor pulmonale, hypoxia, and hypercapnia. Ann Intern Med 1970;72:621-626.

29. Continuous or nocturnal oxygen therapy in hypoxemic chronic obstructive lung disease: a clinical trial. Nocturnal Oxygen Therapy Trial Group. Ann Intern Med 1980;93(3):391-398.

30. Long term domiciliary oxygen therapy in chronic hypoxic cor pulmonale complicating chronic bronchitis and emphysema. Report of the Medical Research Council Working Party. Lancet 1981;1(8222): 681-686.
31. Górecka D, Gorzelak K, Sliwiński P, Tobiasz M, Zieliński J. Effect of long-term oxygen therapy on survival in patients with chronic obstructive pulmonary disease with moderate hypoxaemia. Thorax 1997;52(8):674-679.

32. Stoller JK, Panos RJ, Krachman S, Doherty DE, Make B; Long-term Oxygen Treatment Trial Research Group. Oxygen therapy for patients with COPD: current evidence and the long-term oxygen treatment trial. Chest 2010;138(1):179-187.

33. Department of Health and Human Services Health Care Financing Administration: Criteria for Medicare coverage of oxygen services in the home. Federal Register 1985;50(66):3-4.

34. Timms RM, Kvale PA, Anthonisen NR, Boylen CT, Cugell DW, Petty TL, Williams GW. Selection of patients with chronic obstructive pulmonary disease for long-term oxygen therapy. JAMA 1981; 245(24):2514-2515.

35. Anthonisen NR. Long-term oxygen therapy. Ann Intern Med 1983; 99(4):519-527.

36. Fulmer JD, Snider GL. ACCP-NHLBI national conference on oxygen therapy. Chest 1984;86(5):234-247.

37. Problems in prescribing and supplying oxygen for Medicare patients. Summary of a conference on home oxygen therapy held in Denver, February 28 and March 1, 1986. Am Rev Respir Dis 1986;134(2): 340-341.

38. Carlin BW, Clausen JL, Ries AL. The use of cutaneous oximetry in the prescription of long-term oxygen therapy. Chest 1988;94(2): 239-241.

39. Shigeoka JW, Stults BM. Home oxygen therapy under Medicare. A primer. West J Med 11992;56(1):39-44

40. McCoy RW. Options for home oxygen therapy equipment: storage and metering of oxygen in the home. Respir Care 2013;58(1):65-81; discussion 81-85.

41. Pierson DJ. Translating evidence into practice. Respir Care 2009; 54(10):1386-1401

42. Ashbaugh DG, Bigelow DB, Petty TL, Levine BE. Acute respiratory distress in adults. Lancet 1967;2(7511):319-323.

43. Thompson Reuters Web of Science. Products A-Z. http://thomsonreuters.com/products_services/science/science_products/a-z/ web_of_science. Accessed October 25, 2012.

44. Petty TL. In the cards was ARDS: how we discovered the acute respiratory distress syndrome. Am J Respir Crit Care Med 2001; 163(3 Pt 1):602-603.

45. Ashbaugh DG, Petty TL, Bigelow DB, Harris TM. Continuous positive-pressure breathing (CPPB) in adult respiratory distress syndrome. J Thorac Cardiovasc Surg 1969;57(1):31-41.

46. Petty TL, Ashbaugh DG. The adult respiratory distress syndrome. Clinical features, factors influencing prognosis and principles of management. Chest 1971;60(3):233-239.

47. Ashbaugh DG, Petty TL. Positive end-expiratory pressure. Physiology, indications, and contraindications. J Thorac Cardiovasc Surg 1973;65(1):165-170

48. Bendixen HH, Hedley-Whyte J, Laver MB. Impaired oxygenation in surgical patients during general anesthesia with controlled ventilation. A concept of atelectasis. N Engl J Med 1963;269:991-996.

49. Slutsky AS. American College of Chest Physicians' consensus conference. Chest 1993;104(6):1833-1859. Erratum in: Chest 1994; 106(2):656.

50. The Acute Respiratory Distress Syndrome Network. Ventilation with lower tidal volumes as compared with traditional tidal volumes for acute lung injury and the acute respiratory distress syndrome. N Engl J Med 2000;342(18):1301-1308.

51. Stapleton RD, Wang BM, Hudson LD, Rubenfeld GD, Caldwell ES, Steinberg KP. Causes and timing of death in patients with ARDS. Chest 2005;128(2):525-532. 


\section{Oxygen in Respiratory Care: A Personal Perspective from 40 Years in the Field}

52. Pipeling MR, Fan E. Therapies for refractory hypoxemia in acute respiratory distress syndrome. JAMA 2010;304(22):2521-2527.

53. Liu LL, Aldrich JM, Shimabukuro DW, Sullivan KR, Taylor JM, Thornton KC, Gropper MA. Special article: rescue therapies for acute hypoxemic respiratory failure. Anesth Analg 2010;111(3):693702.

54. Esan A, Hess DR, Raoof S, George L, Sessler CN. Severe hypoxemic respiratory failure: part 1-ventilatory strategies. Chest 2010; 137(5):1203-1216.

55. Raoof S, Goulet K, Esan A, Hess DR, Sessler CN. Severe hypoxemic respiratory failure: part 2-nonventilatory strategies. Chest 2010; 137(6):1437-1448.

56. Diaz JV, Brower R, Calfee CS, Matthay MA. Therapeutic strategies for severe acute lung injury. Crit Care Med 2010;38(8):1644-1650.

57. Nolte D. [Advantages and hazards of oxygen therapy in chronic respiratory insufficiency]. Wien Med Wochenschr 1976;126(23):325329. Article in German.

58. Sassoon CSH, Hassell KT, Mahutte CK. Hyperoxic-induced hypercapnia in stable chronic obstructive pulmonary disease. Am Rev Respir Dis 1987;135(4):907-911

59. Dick CR, Liu Z, Sassoon CS, Berry RB, Mahutte CK. $\mathrm{O}_{2}$-induced change in ventilation and ventilatory drive in COPD. Am J Respir Crit Care Med 1997;155(2):609-614.

60. Petty TL, Stanford RE, Neff TA. Continuous oxygen therapy in chronic airway obstruction. Observations on possible oxygen toxicity and survival. Ann Intern Med 1971;75(3):361-367.
61. Stewart BN, Hood CI, Block AJ. Long-term results of continuous oxygen therapy at sea level. Chest 1975;68(4):486-492.

62. Pierson DJ. The toxicity of low-flow oxygen therapy. Respir Care 1983;28(7):889-897.

63. Benditt JO. Adverse effects of low-flow oxygen therapy. Respir Care 2000;45(1):54-61; discussion 61-64.

64. West GA, Primeau P. Non-medical hazards of long-term oxygen therapy. Respir Care 1983;28(7):906-912.

65. Clark JM. Lambertsen CJ. Pulmonary oxygen toxicity; a review. Pharmacol Rev 1971;23(2):37-133.

66. Deneke SM, Fanburg BL. Normobaric oxygen toxicity of the lung. N Engl J Med 1980;303(2):76-86.

67. Kallet RH, Matthay MA. Hyperoxic acute lung injury. Respir Care 2013;58(1):123-140; discussion 140-141.

68. Pierson DJ, Horton CA, Bates PW. Persistent bronchopleural air leak during mechanical ventilation: a review of 39 cases. Chest 1986; 90(3):321-323.

69. Luks AM, Pierson DJ. Barotrauma and bronchopleural fistula. In: Tobin MJ, editor. Principles and practice of mechanical ventilation, 3rd edition New York: McGraw-Hill; 2013; 1041-1064.

70. Slutsky AS. Ventilator-induced lung injury: from barotrauma to biotrauma. Respir Care 2005;50(5):646-659.

71. Jaecklin T, Otulakowski G, Kavanagh BP. Do soluble mediators cause ventilator-induced lung injury and multi-organ failure? Intensive Care Med 2010;36(5):750-757. 